\title{
Anatomía del sistema caulinar subterráneo de Cyperus corymbosus var. subnodosus (Cyperaceae)
}

\section{Anatomy of the subterranean caulinar system of Cyperus corymbosus var. subnodosus (Cyperaceae)}

\author{
Fernando Heinzen, Julio C. Ramos, Juan C. Tivano \& Abelardo Vegetti \\ Facultad de Ciencias Agrarias, Instituto de Agrobiotecnología (CONICET-Universidad Nacional del Litoral). Kreder 2805 - \\ S3080HOF Esperanza. Provincia de Santa Fe. Argentina. \\ avegetti@fca.unl.edu.ar
}

\begin{abstract}
RESUMEN
Se estudia la anatomía del sistema de ramificación subterráneo en Cyperus corymbosus Rottb. var. subnodosus (Nees et Meyen) Kük. Se describe la anatomía del rizoma y del tubérculo en este taxón. Se realiza un análisis comparativo de las variaciones observadas en diferentes estadios de desarrollo. Las características anatómicas de rizoma y tubérculos están asociadas al típico sistema caulinar subterráneo, a la forma de crecimiento de la especie y a su modo de propagación vegetativa.
\end{abstract}

Palabras clave: Histología, rizoma, tubérculo, Cyperus corymbosus, Cyperaceae.

\begin{abstract}
The anatomy of the underground branching systems in Cyperus corymbosus Rottb. var. subnodosus (Nees et Meyen) Kük. was examined. The anatomy of the rhizome and tuber of this taxon. A comparative analysis of the variations observed in different development stages was also performed. The anatomical characteristics of the rhizome and tubers are associated with the typically underground shoot system, the growth form of the species and its mode of vegetative propagation.
\end{abstract}

KeYwords: Histology, rhizome, tuber, Cyperus corymbosus, Cyperaceae.

\section{INTRODUCCIÓN}

La familia Cyperaceae incluye aproximadamente 5.000 especies (Simpson et al. 2007), de las cuales 220 han sido reportadas como malezas. Aproximadamente un $42 \%$ de estas especies pertenecen al género Cyperus L. (Bendixen \& Nandihalli 1987). Entre éstas sobresale Cyperus rotundus L., que fue considerada como la peor maleza del mundo, sobre la base del número de países donde se la ha encontrado como maleza seria, principal o común (Holm et al. 1977). $\mathrm{Su}$ gran agresividad se debe a un sistema de ramificación subterráneo complejo y extendido, integrado por cormos basales ligeramente engrosados, rizomas y tubérculos (Betria 1973); la multiplicación por tubérculos y cormos basales es el medio de mayor dispersión (Justice \& Whitehead 1946, Loustalot et al. 1954, Hauser 1962). Cyperus corymbosus
Rottb. var. subnodosus (Nees et Meyen) Kük. es una especie de América tropical y andina (Barros 1947) que se extiende desde los valles cordilleranos hasta los llanos más bajos y pantanosos del litoral Atlántico, prefiriendo especialmente los sitios deprimidos con anegamientos temporarios (Vegetti 1993). Se trata de una especie que también se propaga vegetativamente por rizomas y tubérculos; y que se ha extendido en los últimos años disminuyendo el valor de los campos de pastoreo (Hilguert 1993).

No existe un trabajo de conjunto que caracterice la anatomía del sistema caulinar subterráneo de C. corymbosus var. subnodosus ni los cambios que ocurren en esas estructuras a lo largo de la ontogenia de la planta. En Cyperaceae, las investigaciones de este tipo están estrechamente relacionadas con la dinámica estacional del crecimiento y la supervivencia de los vástagos (Alexeev 1988). 
Cyperus corymbosus var. subnodosus es una hierba perenne que produce un sistema subterráneo de vástagos simpodiales compuestos de rizomas y tubérculos. El tallo aéreo es foliado en la base, de $40-120 \mathrm{~cm}$ de altura, y remata en una inflorescencia en antela de espiguillas pseudolateral (Heinzen \& Vegetti 1994).

Si bien produce abundantes semillas, la reproducción por esta vía es escasa o nula, no habiéndose encontrado plántulas en las comunidades estudiadas. Bajo condiciones controladas en laboratorio fue posible lograr la germinación de dichas semillas, a pesar de que su poder germinativo fue muy bajo. Consecuentemente, la especie se reproduce principalmente por multiplicación vegetativa. Ésta ocurre en primavera-verano por la producción de rizomas de longitud variable $(0,5-12 \mathrm{~cm})$ a partir de yemas axilares de los tubérculos producidos en años anteriores o en el mismo año (Heinzen 1993).

En las especies cuya dispersión y competencia se basa en su prolífico sistema de ramificación vegetativo, el análisis anatómico secuencial del desarrollo de todos los vástagos resulta fundamental para comprender no sólo los patrones de crecimiento sino también su capacidad de infestación. Por ello el objetivo de este trabajo es estudiar la anatomía y desarrollo de los sistemas de ramificación subterráneos de C. corymbosus var. subnodosus.

\section{MATERIAL Y MÉTODOS}

El muestreo se realizó en los departamentos La Capital y Las Colonias de la Provincia de Santa Fe (Argentina). De cada población se tomó un cuadrado de $30 \mathrm{~cm}$ de lado, se extrajo el pan de tierra y se lavó con agua para recuperar intacto el sistema subterráneo; una parte (20 tubérculos) fueron plantados en macetas plásticas tipo agropol con arena y tierra. Las plantas fueron cultivadas en invernadero. Se realizó un seguimiento de la brotadura y crecimiento de las yemas axilares. Se caracterizó el sistema caulinar subterráneo.

Muestras de rizomas y tubérculos en dos diferentes estadios de desarrollo (jóvenes y adultos) fueron fijadas en F.A.A. (formol, alcohol 70\%, ácido acético), desilicificadas con ácido fluorhídrico al $10 \%$, deshidratadas en una serie de alcohol-xilol e incluidas en parafina-cera. Las muestras fueron cortadas transversalmente a $15 \mu \mathrm{m}$ de espesor con micrótomo rotativo y teñidas con Safranina Fast-Green (Berlyn \& Miksche 1976). Los esquemas se hicieron con cámara clara y las fotomicrografías fueron tomadas desde un microscopio Olympus BH.

Los ápices de los vástagos subterráneos destinados al estudio de desarrollo fueron deshidratados en alcohol $50^{\circ}$, $75^{\circ}$ y $96^{\circ} \mathrm{y}$, finalmente, con acetona. Las muestras fueron secadas mediante la técnica de Punto Crítico, metalizadas y observadas al microscopio electrónico de barrido (MEB - Universidad del Sur).
Para la caracterización anatómica de los dos tipos de órganos subterráneos se siguió el criterio de Metcalfe (1971), que menciona como tejidos constitutivos del rizoma en Cyperaceae: epidermis, hipodermis, esclerénquima, corteza, capa endodermoide, haces vasculares, cavidades de aire y células secretoras (idioblastos).

\section{Material estudiado}

ARGENTINA, Prov. Santa Fé. Sto. Tomé, sobre Ruta 19, 29-XII-1993, Vegetti 1149 (SF). Nelson, sobre Ruta 11, potrero inundado, 29-XII-1993, Vegetti 1150 (SF). Iriondo, sobre Ruta 11, 29-XII-1993, Vegetti 1151 (SF). N de Candioti, sobre Ruta 11, 29-XII-1993, Vegetti 1152 (SF). N de Recreo, sobre Ruta 11, 29-XII-1993, Vegetti 1153 (SF). Ruta 70, cruce con camino a empalme San Carlos, potrero, 13-XII-1994, Vegetti 1175 (SF).

\section{RESULTADOS}

Los catafilos de rizoma y tubérculo se disponen en filotaxis espirotrística (Fig. 1). Los rizomas pueden presentar yemas axilares (Fig. 1 A), pero éstas no desarrollan. Posteriormente al crecimiento en longitud del rizoma, en la región apical los entrenudos comienzan a engrosarse y acortarse, originándose el tubérculo (Fig. 1 D, E). En los inicios de la tuberización se produce la diferenciación de yemas en las axilas de los primordios foliares (Fig. 1 C). A partir de las yemas axilares del tubérculo se formarán nuevos rizomas y desde la yema apical se generará el vástago aéreo. A medida que los frutos del vástago aéreo maduran y caen, el crecimiento en grosor de los tubérculos aumenta. Llegado el invierno la totalidad de los vástagos aéreos se hielan, persistiendo solamente el sistema caulinar subterráneo como forma de propagación de la especie.

Los tubérculos pueden producir 1-3 rizomas; en los casos que el tubérculo forme un solo rizoma éste sigue más comúnmente la dirección del rizoma madre; si se forman dos rizomas lo más frecuente es que cada nuevo rizoma forme un ángulo de $45^{\circ}$ grados respecto a la dirección de crecimiento del rizoma madre, hacia la derecha y la izquierda, respectivamente. En el caso que el tubérculo forme 3 rizomas uno sigue la dirección del eje madre y los otros forman ángulo de aproximadamente $45^{\circ}$ grados hacia la derecha y hacia la izquierda, respectivamente de la dirección de crecimiento del rizoma madre.

En el rizoma joven (Fig. 2 A-C) el parénquima cortical es uniforme con muy pequeños espacios intercelulares e idioblastos que contienen productos fenólicos; no se reconoce claramente la hipodermis del resto del parénquima cortical; ya está esbozado el anillo de esclerénquima cuyas células presentan paredes delgadas; al igual que las células de la vaina de los haces anfivasales de la estela. 
El rizoma adulto de C. corymbosus var. subnodosus (Fig. 2 D-F) consta de epidermis uniestratificada con cuerpos de sílice y cutícula gruesa; hipodermis de 5-7 capas de células poligonales; cordones subepidérmicos de esclerénquima pulviniformes. Córtex interno con cavidades de aire grandes y numerosos idioblastos; anillo de esclerénquima, en la parte más interna del córtex adyacente a la capa endodermoide, bien diferenciado con células de paredes muy engrosadas; capa endodermoide difusa entre las capas de células del córtex y la estela. Cilindro vascular con idioblastos, en proporción y características similares a las del córtex, y con la capa de células más externas con paredes engrosadas; haces vasculares corticales escasos, colaterales y con vaina de células engrosadas; haces vasculares de la estela anfivasales dispuestos en 2-4 anillos y con vaina de células de paredes engrosadas (Fig. 2 F). Se destaca la lignificación de las capas de células corticales internas, y de las capas de células externas de la estela, limitantes con la capa endodermoide (Fig. 2 F).

En el tubérculo joven (Fig. 3 A-B) ya se distingue la región hipodérmica y las células precursoras del anillo de esclerénquima; el grado de esclerificación de las células de ésta última región así como de las células de la vaina del haz es escaso.

El tubérculo adulto de C. corymbosus var. subnodosus (Fig. 3 C-D) está formado por epidermis uniestratificada con cuerpos de sílice y cutícula gruesa; hipodermis de 3-7 capas de células grandes suberificadas; cordones subepidérmicos de esclerénquima pulviniformes, algunos fusionados. Corteza de menor grosor que la estela con abundantes idioblastos; anillo de esclerénquima, adyacente a la hipodermis, bien diferenciado formado por braquiesclereidas; capa endodermoide de células pequeñas con engrosamientos en U. Cilindro vascular, que ocupa mayor volumen que la corteza, formado por parénquima reservante con abundantes idioblastos; haces vasculares corticales escasos, colaterales, con vaina de células de paredes engrosadas; haces vasculares de la estela abundantes, anfivasales con vaina de células pequeñas y de paredes engrosadas, dispersos por todo el parénquima, no fusionados.

Cuando los entrenudos apicales del rizoma (Fig. 2 D-F) generan un tubérculo (Fig. 3 C-D) se observan las siguientes variaciones: 1) disminuye el número de capas de hipodermis; 2) no se forman cavidades aéreas, en consecuencia el parénquima cortical es compacto; 3) el anillo de esclerénquima, que en el rizoma era interno se ubica adyacente a la hipodermis; 4) no se produce la lignificación de las capas de células corticales internas, y de las capas de células externas de la estela, limitantes con la capa endodermoide; 5) aumenta el número de células parenquimáticas en la estela; 6) se presenta, consecuentemente, una menor densidad de haces en la estela.

Las modificaciones que le ocurren a un rizoma joven (Figs. 2 A-C, 4 A) cuando madura (rizoma adulto, Fig. 2 DF; Fig. 4 B) se relacionan con: 1) aumento del grosor de la cutícula; 2) el desarrollo de cavidades de aire y diferenciación de hipodermis y parénquima cortical interno; 3 ) la formación del anillo de esclerénquima; 4) la esclerificación de la vaina de los haces vasculares; 5) el aumento de la lignificación y espesor de las paredes de los elementos traqueales; 6) mayor diferenciación de idioblastos. Con el tiempo, por el gran desarrollo de las cavidades de aire, se va a producir el desprendimiento de la epidermis, hipodermis y parte media y superficial del córtex, el rizoma va a quedar constituido exclusivamente por las células más internas del córtex y el cilindro vascular.

Si se compara la anatomía de un tubérculo joven (Figs. 3 A-B, 4 C) y uno adulto (Figs. 3 C-D, 4 D) se observa: 1) aumento del espesor de las paredes de las células hipodérmicas; 2) formación del anillo superficial de esclerénquima; 3) incremento del espesor y la lignificación de las paredes de las células de la vaina del haz; 4) mayor número y grado de diferenciación de los idioblastos; 5) aumento del grosor del cilindro vascular; 6) aumento del tamaño de los cordones subepidérmicos de esclerénquima. 

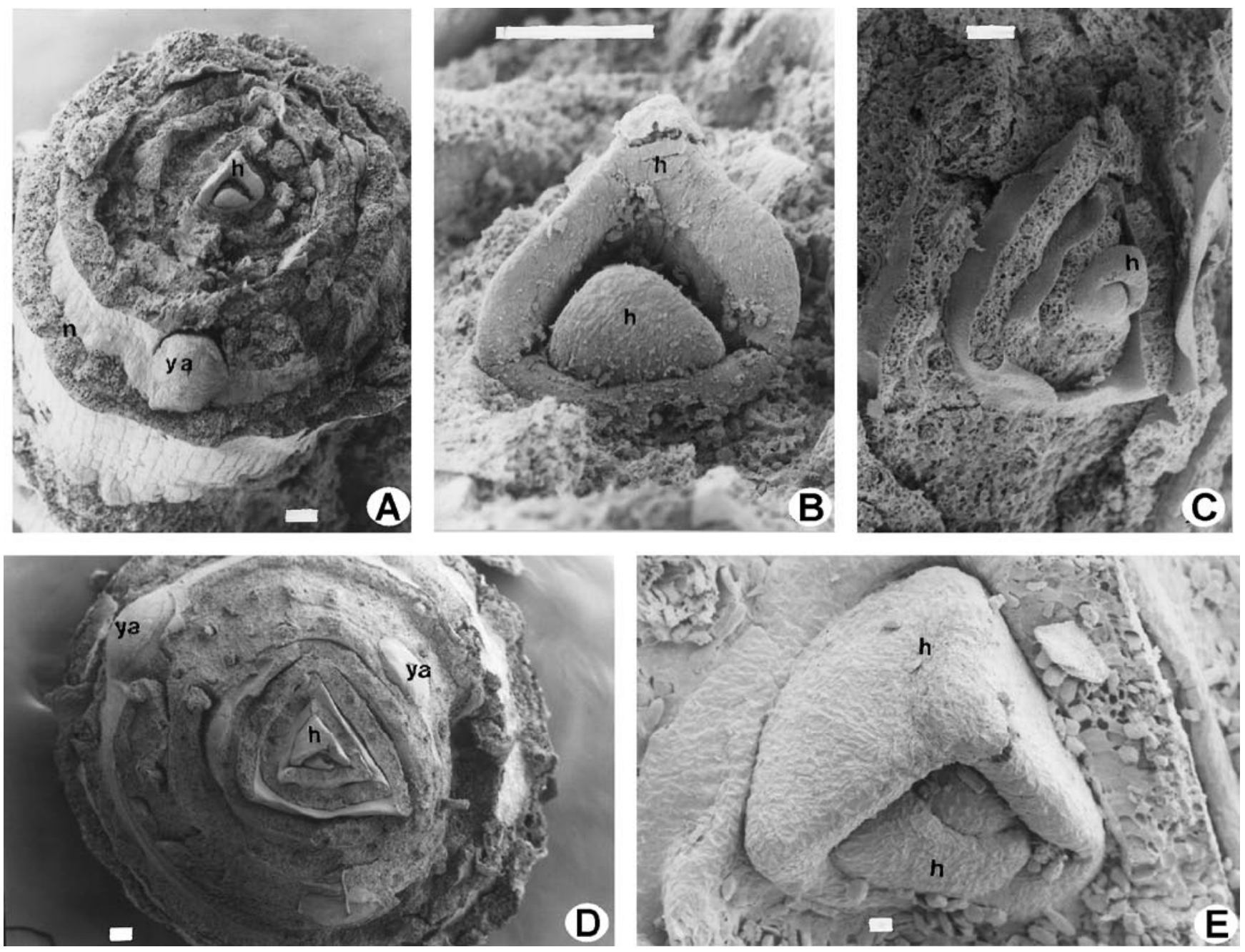

FIGURA 1. Fotomicrografías de yemas en rizoma y tubérculo de Cyperus corymbosus var. subnodosus, MEB. A: Sector apical de un rizoma. B: Detalle del ápice del rizoma; C: Yema axilar en tubérculo madre. D: Zona apical del tubérculo. E: Ápice del tubérculo. Referencias: h, catafilo envainador; n, nudo; ya, yema axilar. Escala: A - D: $100 \mu \mathrm{m}$; E: $10 \mu \mathrm{m}$.

FIGURE 1. Photomicrographs buds of the rizome and the tuber of Cyperus corymbosus var. Subnodosus, SEM. A: Apical part of the rizome. B: Detaill of the rizome apex; C: Axillar bud of the mother tuber. D: Apical zone of the tuber apex. E: Tuber apex. References: h, sheating cataphyll; n, node; ya, axillary bud. Scale bar: A - D: $100 \mu \mathrm{m}$; E: $10 \mu \mathrm{m}$. 

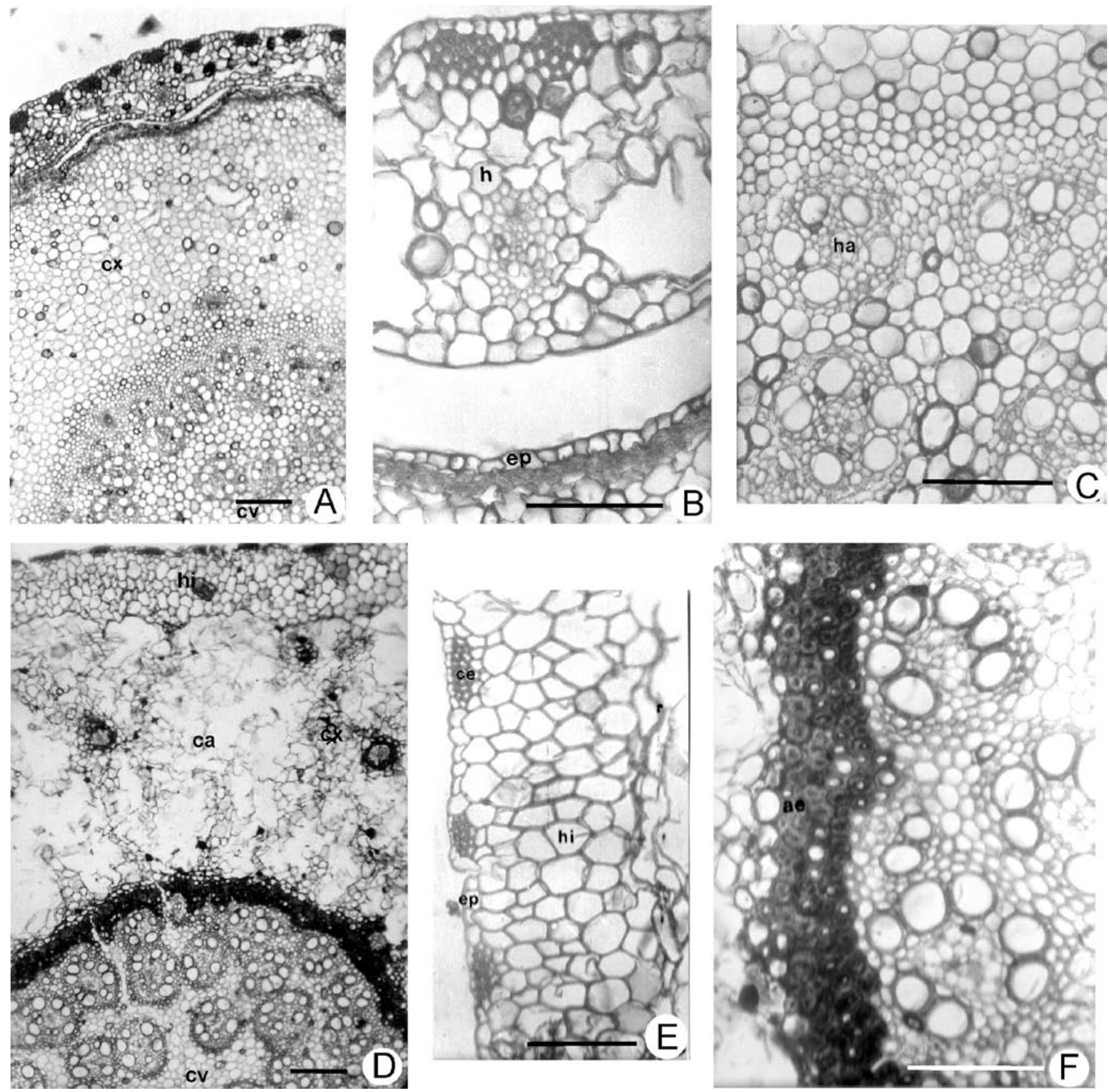

Figura 2. Cortes transversales de rizoma en Cyperus corymbosus var. subnodosus: A - C: Rizoma joven, A: Vista general; B: Catafilo envainador y epidermis del rizoma; C: Detalle de la estela. D - F: Rizoma adulto: D: Vista general; E: Zona de la epidermis, hipodermis y cordones de esclerénquima; F: Detalle del anillo de esclerénquima, capa endodermoide y haces anfivasales de la estela. Referencias: ep, epidermis; hi, hipodermis; ce, cordones de esclerénquima; cx, córtex; ha, haz anfivasal; ae, anillo de esclerénquima; ca, cavidad aérea; cv, cilindro vascular; h, catafilo. Escala: $10 \mu \mathrm{m}$.

Figure 2. Cross sections of the rizome in Cyperus corymbosus var. subnodosus: A - C: Young rizome, A: General view; B: sheating cataphyll and rizome epiderm; C: Stele detaill. D - F: Adult rizome: D: General view; E: Region of the epiderm, hipoderm and sclerenchyma strands; F: Detail of the sclerenchyma ring, endodermoid layer and anfivasal bundle of the stele. References: ep, epiderm; hi, hipoderm; ce, sclerenchyma strands; cx, cortex; ha, anfivasal bundle; ae, sclerenchyma ring; ca, air cavity; cv, vascular cylinder; h, cathaphyll. Scale bar: $10 \mu$ m. 

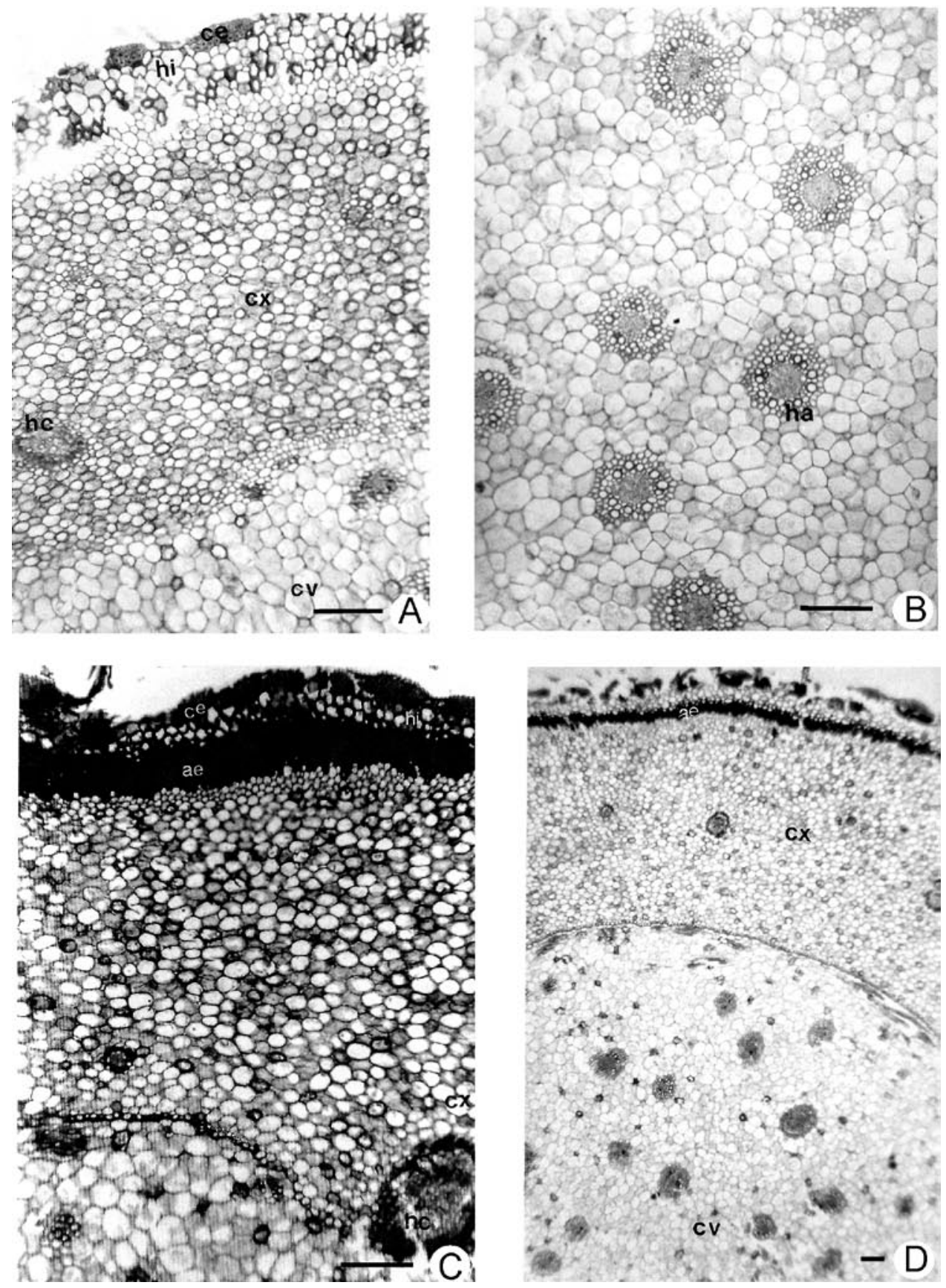

Figura 3. Cortes transversales de tubérculo en Cyperus corymbosus var. subnodosus. A - B: Tubérculo joven. A: Vista general; B: Haces anfivasales de la estela; C - D: Tubérculo adulto: C: Epidermis, hipodermis, anillo de esclerénquima y córtex; D: Vista general. Referencias: hi, hipodermis; ce, cordones de esclerénquima; cx, córtex; hc, haz colateral; ha, haz anfivasal; ae, anillo de esclerénquima; cv, cilindro vascular. Escala: $10 \mu \mathrm{m}$.

Figure 3. Cross sections of the tuber in Cyperus corymbosus. var. subnodosus. A - B: Young tuber. A: General View; B: Anfivasal bundle of the stele; C - D: Adult tuber: C: Epiderm, hipoderm, sclerenchyma ring and cortex; D: General view. References: hi, hipoderm; ce, sclerenchyma strands; cx, cortex; hc, collateral bundle; ha, anfivasal bundle; ae, sclerenchyma ring; cv, vascular cylinder. Scale bar: $10 \mu \mathrm{m}$. 

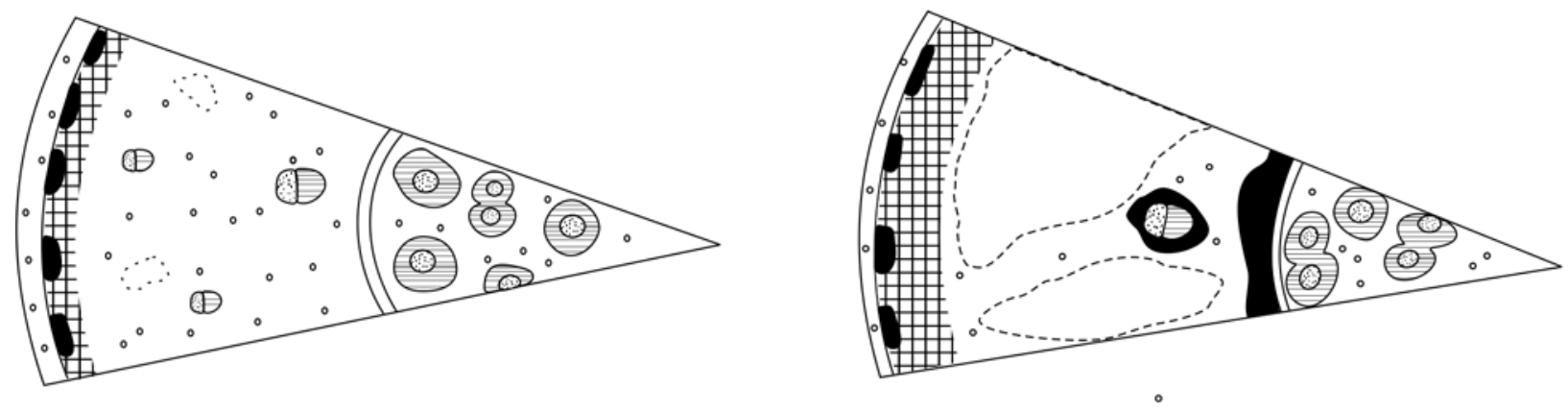

A
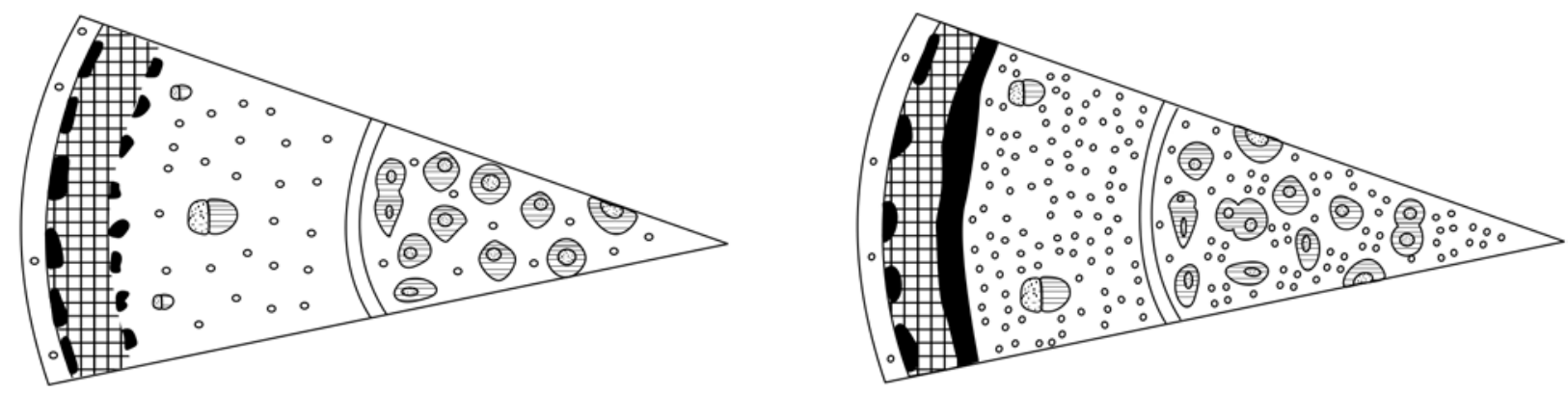

C

FIgURA 4. Esquemas comparativos de la anatomía del rizoma y tubérculo de C. corymbosus var. subnodosus en dos estadios de desarrollo: A: rizoma joven; B: rizoma adulto; C: tubérculo joven; D: tubérculo adulto. Símbolos: epidermis y capa endodermoide, se han representado con una banda blanca continua; las células secretoras, con círculos; la hipodermis con celdillas horizontales y las cavidades aéreas se encuentran limitadas por líneas de puntos. Los restantes símbolos según Metcalfe y Chalk (1957).

Figure 4. Comparative diagrams of the anatomy of the rizome and the tuber of C. corymbosus var. subnodosus: A: Young rizome; B: Adult rizome; C: Young tuber; D: Adult tuber. Symbols: white, epiderm and endodermoid layer; circles, secretory cells; horizontal cells, hipodermis; dotted lines, aerial cavities. The others symbols accord Metcalfe y Chalk (1957).

\section{DISCUSIÓN}

En los órganos subterráneos de las especies de Cyperus los cordones subepidérmicos de esclerénquima junto con la epidermis aumentan la resistencia a la desecación (Betría 1973); esta protección es mayor en los tubérculos, donde dichos cordones se encuentran fusionados. El engrosamiento y lignificación de las fibras de los cordones esclerenquimáticos subepidérmicos está correlacionada con la presencia de cuerpos de sílice en las células epidérmicas (Mehra \& Sharma 1965, 1969). Estas células epidérmicas lindantes con los cordones de esclerénquima son siempre de menor profundidad que el resto de las células de la epidermis (Govindarajalu 1974, Esau 1976).

El espesor del córtex y el grado de desarrollo de los espacios intercelulares de los rizomas varía en las diversas especies de Cyperus (Shah 1967, Metcalfe 1971, Gifford \& Bayer 1995). En C. corymbosus var. subnodosus las células de la hipodermis tienen paredes delgadas en el rizoma (Fig. 2 E) y engrosadas en el tubérculo adulto (Fig. 3 C). En C. giganteus Vahl la hipodermis del rizoma se forma por divisiones de capas subepidérmicas y es considerada el córtex externo claramente diferenciado del córtex interno con abundantes cavidades de aire (Rodrigues \& Estelita 2002, 2009).

En Cyperaceae las cavidades de aire en el rizoma, son importantes para la aireación (Wille 1926), para el transporte de gases (Armstrong 1979, 1989) y el metabolismo aeróbico de rizomas y raíces (Brix 1989, 1990, Li \& Jones 1995). En Cyperus corymbosus var. subnodosus el escaso y débil parénquima que las forma ( Fig. 2 D) es la región por donde se produce el desprendimiento de epidermis y córtex externo 
en los rizomas viejos. En cambio en los tubérculos (Fig. 3 D) el cortex es compacto y persistente por estar encerrado y protegido por el anillo de braquiesclereidas y por la hipodermis suberificada.

La reserva en un rizoma joven ocurre en el córtex y en el cilindro vascular; en estadios posteriores (rizoma adulto) la corteza pierde generalmente la función de almacenamiento y conserva la función mecánica y de aireación (Wille 1926). En los rizomas tipo C. corymbosus var. subnodosus finalmente también se pierde la función de aireación pues se destruyen las cavidades de aire del córtex interno y cae el córtex externo; quedando sólo el resto del córtex que persiste con función mecánica.

La ocurrencia de endodermis en rizomas de Cyperaceae ha sido mencionada por distintos autores (Evans 1965, Eiten 1969, Wills \& Briscoe 1970, Sharma \& Mehra 1972, Govindarajalu 1974, Wills et al. 1980, Wills 1987, Rodrigues \& Estelita 2002, 2009, Alonso \& Moraes-Dallaqua 2004, Menezes et al. 2005). Otros autores no identificaron una verdadera endodermis en la capa más interna del córtex y denominaron a esa zona capa endodermoide (Plowman 1906, Kukkonen 1967, Metcalfe 1971, Rudall 1984). Para C. corymbosus var. subnodosus en dicha capa no se observó presencia de banda de Caspary, un carácter mencionado para C. esculentus L. (Gifford \& Bayer 1995).

En el rizoma de las diversas especies de Cyperus se presentan variaciones en el grado de lignificación de la capa endodermoide y los tejidos vecinos (Plowman 1906). El grado de lignificación que se observa en C. corymbosus var. subnodosus en las capas internas del córtex y externas del cilindro vascular lindantes con la capa endodermoide también fue observado en otras especies de Cyperus (Wille 1926, Wills \& Briscoe 1970, Wills 1975, Wills et al. 1980, Rodrigues \& Estelita 2002). Esta intensa lignificación que presentan dichas células (Fig. 2 F) fue relacionada con la resistencia a daños (Lorougnon 1969, Wills \& Briscoe 1970, Wills 1975,1987$)$ y en C. corymbosus var. subnodosus es responsable de mantener protegido al cilindro vascular cuando la epidermis, hipodermis y parte del córtex se desprende.

Los haces vasculares anfivasales (Figs. 2, 3) se localizan, en varios anillos, en la estela como es común en especies de Cyperus y de Cyperaceae en general (Wille 1926, D`Almeida \& Ramaswamy 1948, Mani 1963, Shah 1967, Metcalfe 1971, Rodrigues \& Estelita 2002, Prata et al. 2007), y pueden llegar a fusionarse principalmente en los rizomas (Figs. 2, 4 B) por el menor diámetro de la estela.

En diversos géneros y especies de Cyperaceae han sido descriptos idioblastos conteniendo compuestos fenólicos, taninos, resinas o aceites esenciales (Wille 1926, Metcalfe 1971, Shah 1967, Mehra \& Sharma 1969, Betría 1973, Govindarajalu 1974, Estelita 1993, Estelita \& Caldeira 1997, Rodrigues \& Estelita 2002, 2009, Zoghbi et al. 2006). En Cyperus corymbosus var. subnodosus los idioblastos se encuentran en el córtex (tanto interno como externo), cilindro vascular y, en menor medida, en la epidermis (Figs. 2, 3).

En el tubérculo de Cyperus corymbosus var. subnodosus (Figs. 3 C, 4 C) el anillo de braquiesclereidas, que se forma por debajo de la hipodermis, colabora con la resistencia a daños externos, evita la desecación y mantiene intactas las reservas de las células corticales para una futura brotación. En los tubérculos (Figs. 3, 4 C, D) tanto el córtex como el cilindro vascular tienen alta proporción de parénquima. El cilindro vascular, a pesar de contener la mayor parte del tejido vascular, presenta un gran volumen de parénquima interfascicular determinando que los haces vasculares se distribuyan laxamente, tal como fuera descripto para Cyperus rotundus (Wills 1987).

El rizoma provee de pocos caracteres de interés taxonómico (Metcalfe 1971). Las principales diferencias en la anatomía de los rizomas de especies de Cyperus (Mehra \& Sharma 1969, Metcalfe 1971, Govindarajalu 1974) se relacionan con diferentes formas de crecimiento, asociadas a rizomas con variaciones en el grado de engrosamiento y la longitud de los entrenudos. Algunas especies como C. giganteus y C. papyrus L. (Haines \& Lye 1983, Goetghebeur 1998, Rodrigues \& Estelita 2002) presentan un rizoma grueso, congesto, con entrenudos muy cortos. Por el otro lado, C. rotundus, C. esculentus, C. tuberosus Rottb., C. aureus Ten. y C. corimbosus var. subnodosus presentan rizomas muy delgados y de entrenudos más largos (caracterizados a veces como estoloníferos) que engrosan sus porciones apicales produciendo tubérculos (Lorougnon 1969, 1970, Mehra \& Sharma 1969, Betría 1973, Haines \& Lye 1983, Stoller \& Sweet 1987, Heinzen \& Vegetti 1994, Goetghebeur 1998). La presencia y desarrollo de yemas axilares ocurre en los rizomas gruesos y cortos y en los tubérculos; en los rizomas delgados y de entrenudos largos las yemas axilares, si presentes (Fig. 1 A), no desarrollan. En el rizoma de C. giganteus (Rodrigues \& Estelita 2002), Cyperus odoratus L., Hypolytrum schraderianum Nees, Fuirena umbellata Rottb., Bulbostylis paradoxa (Spreng.) Lindm. (Rodrigues \& Estelita 2009), la actividad del meristema de engrosamiento primario (MEP) produce un grueso córtex que tiene un origen mixto: el cortex externo se origina del meristema fundamental derivado del ápice, y el córtex interno deriva del MEP. En estas especies el MEP tiene actividad bidireccional amplificando considerablemente el grosor del córtex; y además se forma un meristema de engrosamiento secundario (MES) que contribuye al engrosamiento del rizoma; en tanto que, en el otro tipo de rizomas sólo se presenta el MEP periférico sólo con actividad centrífuga, como fue estudiado para Cyperus rotundus y C. esculentus (Gifford y Bayer 1995, Rodrigues \& Estelita 2009). El MEP y su continuidad el MES generan el grueso rizoma en Cyperus giganteus, $C$. odoratus, Hypolytrum schraderianum, Fuirena umbellata y 
Bulbostylis paradoxa, y la ausencia de meristema intercalar determina el rizoma congesto de entrenudos cortos de estas especie (Rodrigues \& Estelita 2002, 2009). Es importante remarcar que el MEP y el MES en las Monocotiledóneas son fases diferentes del mismo meristema; y que el crecimiento secundario es considerado un carácter primitivo (Rodrigues \& Estelita 2002). Los rizomas delgados podrían ser considerados como tallos más especializados en los que está ocurriendo una reducción de la actividad del MEP (Rodrigues \& Estelita 2009).

En los rizomas largos y delgados la epidermis, la hipodermis y parte del córtex interno se desprenden quedando sólo las capas lignificadas del córtex interno y del cilindro vascular muy lignificadas como fuera descripto para C. rotundus, C. esculentus (Wills \& Briscoe 1970, Wills 1975) y en este trabajo para C. corymbosus var. subnodosus. En este estado el rizoma funciona como conector ("spacer") entre la planta y los tubérculos o de los tubérculos entre sí.

Las variaciones en las formas de crecimiento de los rizomas de las especies de Cyperus están directamente relacionadas con la propagación vegetativa de la especie y, fundamentalmente, con su capacidad invasora, un carácter muy importante en las especies de Cyperus malezas de cultivos o de campos de pastoreo. Los rizomas largos permiten espaciar grandemente los ramets respecto del vástago madre, con lo que se evita la competencia entre ramets; en tanto que los rizomas cortos permiten una expansión lenta generando el crecimiento en superficie de la mata, la que se comporta como un genet de ramets densamente dispuestos (Bernard 1986). Schmid y Harper (1985) distinguen formas de crecimiento "tipo falange" de las "tipo guerrilla". Las primeras son plantas de estructura compacta con conexiones cortas entre los ramets. En tanto que las "tipo guerrilla" presentan estructuras pobremente agregadas con conexiones largas entre los ramets. Las formas de crecimiento "tipo falange" forman matas restringidas a un lugar y presentan una alta tasa de floración y producción de semillas. Las formas de crecimiento "tipo guerrilla" se desarrollan rápidamente con una tasa de crecimiento independiente de la densidad y son capaces, debido a sus rizomas o estolones, de explorar rápidamente un espacio abierto; tienen una gran habilidad competitiva. Las especies con rizomas largos como Cyperus corymbosus var. subnodosus presentan una estrategia de crecimiento "en guerrilla"; a diferencia de ellas las especies de Cyperus con rizomas cortos presentan una estrategia "en falange", caracterizada por una menor habilidad competitiva (Schmid \& Harper 1985).

La propagación vegetativa de las especies con sistema caulinar subterráneo como el de Cyperus corymbosus var. subnodosus es importante especialmente en la dispersión y ocupación del espacio (Sculthorpe 1967). En algunas especies ha sido estudiado que un determinado número de estos tubérculos permanece en dormancia durante cierto tiempo; una alta proporción de tubérculos en latencia en poblaciones naturales y la posibilidad de los tubérculos de permanecer durmientes durante un largo tiempo puede posibilitar el rebrote con posterioridad a daños severos o a condiciones ambientales desvaforables (Hroudová \& Zákravsky 1995).

Según Kron y Stewart (1994) la organización espacial de una planta proviene de la intersección de un componente dinámico del crecimiento (predisposición a producir nuevos módulos), y un componente espacial (el posicionamiento de los módulos). El componente dinámico se relaciona con los patrones de desarrollo en los meristemos, ofreciendo unidades vegetativas nuevas o florales; el componente espacial está determinado por la longitud de las unidades espaciales y el ángulo de ramificación (Bell \& Tomlinson 1980). En Cyperus corymbosus los meristemos productores de nuevos vástagos vegetativos subterráneos son las yemas axilares de los tubérculos, mientras que la yema apical origina el tallo florífero, manifestando de este modo el crecimiento simpodial de la especie. Las yemas axilares de los tubérculos son el punto de origen del modelo de crecimiento subterráneo de la planta, y por consiguiente de la organización espacial del sistema subterráneo; y los factores que controlan la iniciación de un nuevo rizoma gobiernan el desarrollo arquitectural del sistema (Bell 1986). La geometría de los patrones de ramificación de los tubérculos está dada por la producción de 1-3 ramificaciones. El modelo de crecimiento del rizoma de Cyperus corymbosus se adapta al modelo lineal descrito por Bell \& Tomlinson (1980), aunque con ciertas variaciones porque el sistema en esta especie es capaz de producir ramificaciones hacia la izquierda y derecha de la línea de dirección del rizoma que lo precede. Posiblemente las variaciones que se presentan en el modelo arquitectural de estos rizomas sean debidas a condiciones ambientales, factores fisiológicos, fenómenos de envejecimiento dentro del clon o a la interacción entre plantas; desviaciones en los patrones de crecimiento que son esperadas en organismos que crecen bajo condiciones naturales (Kron \& Stewart 1994).

Las principales variaciones que ocurren en los tejidos del rizoma de Cyperus corymbosus var. subnodous a lo largo de la ontogenia (Figs. 2, 4 A, B) relacionadas con el comportamiento del rizoma en la propagación vegetativa de la especie son: 1) el gran desarrollo de las cavidades de aire y el consecuente desprendimiento de la corteza externa y la epidermis; 2) el aumento del espesor y la lignificación de las paredes celulares de las capas internas del córtex y externas del cilindro vascular lindantes con la capa endodermoide, que otorga protección al cilindro vascular una vez caída la epidermis y parte del córtex.

El tubérculo persistirá como propágulo, por ello a lo largo de la ontogenia del tubérculo (Figs. 3, 4 C-D): 1) aumenta el espesor de las paredes celulares de la hipodermis y del anillo de esclerénquima; y 2) a su vez se incrementa la proporción 
de parénquima cortical y del cilindro vascular. Dichos cambios se relacionan, en el primer caso, con la protección de los tejidos internos que aseguran la persistencia ante condiciones ambientales desfavorables de esta estructura de propagación; y, en el segundo caso, con la disponibilidad de reservas que posibilitarán el rebrote frente a condiciones ambientales favorables.

\section{BIBLIOGRAFÍA}

Alexeev, Y.E. 1988. Ontogenesis in Carex species. Aquatic Botany 30: 39-48.

Alonso, A.A. \& M. Moraes-Dallaqua. 2004. Morfoanatomia do sistema caulinar de Canna edulis Kerr-Gawler (Canaceae). Revista Brasileira de Botânica 27: 229-239.

Armstrong, W. 1979. Aeration in higherplants. Advances in Botanical Research. 6: 225- 332.

Armstrong, W. 1989. Aeration in roots. In: J. H. Cherry (ed.), Environmental stress in plants. Pp. 197-206. Springer. Berlin.

Barros, M. 1947. Cyperaceae. En: Genera et Species Plantarum Argentinarum. Tomo IV (I y II). (ed. H. Decole), pp. 1539. Kraft. Buenos Aires.

BeLL, A. 1986. The simulation of branching patterns in modular organisms. Philosophical Transactions of the Royal Society of London, Series B 313: 143-159.

Bell, A. \& P.B. Tomlinson. 1980. Adaptive architecture in rhizomatous plants. Journal of the Linnean Society, Botany 80: $125-160$.

Bendixen, L.E \& U.B. Nandihalli. 1987. Worldwide distribution of purple and yellow nutsedge (Cyperus rotundus and $C$. esculentus). Weed Technology 1: 61-65.

Berlyn, G.P. \& J. P. Miksche. 1976. Botanical microtechnique and cytochemistry. Iowa State University Press, Ames, IA. 336 pp.

BERNARD, J.M. 1986. Life history and vegetative reproduction in Carex. Canadian Journal of Botany 68: 1441-1448.

BetriA, A.I. 1973. Biología del cípero (Cyperus rotundus L.). Revista de la Facultad de Agronomía de La Plata, 3a. época, 49: 181-199.

BRIX, H.1989. Gas exchange through dead culms of reed, Phragmites australis (Cav.) Trin. Ex Steudel. Aquatic Botany 35: 81-89.

BRIX, H. 1990. Gas exchange through the soil-atmosphere interphase and through dead culms of Phragmites australis in a constructed reed bed receiving domestic sewage. Water Research 24: 259-266.

D'Almeida, J.F. \& C.S. Ramaswamy. 1948. A contribution to the study of the ecological anatomy of the Indian Cyperaceae. University Bombay Botanical Memorial 1: 1-63.

EITEN, L.T. 1969. The vegetative anatomy of Eleocharis interstincta (Vahl.) Roem \& Shult. Arquivos de Botânica do Estado de São Paulo 4: 187-228.

EsAu, K. 1976. Anatomía Vegetal. Ed. Omega. Barcelona. 779 pp.

Estelita, M.E. 1993. Anatomía dos órgãos vegetativos de Remirea maritima Aubl. (Cyperaceae). Naturalia 18: 123-134.

Estelita, M.E. \& W. Caldeira. 1997. Ultrastructure of phenolic storage cells in leaf and scape of Cyperus obtusatus
(Cyperaceae), a Kranz species. Acta Microscopica 6, Supl. 8: $642-643$.

Evans, P.S. 1965. Intercalary growth in the aerial shoot of Eleocharis acuta R. Br. Prodr. I. Structure of the growing zone. Annals of Botany 29: 205-217.

Gifford, E.M. \& D.E. BAYER 1995. Developmental anatomy of Cyperus esculentus (yellow nutsedge). International Journal of Plant Sciences 156: 622-629.

Goetghebeur, P. 1998. Cyperaceae. In: K. Kubitzki, H. Huber, P.J. Rusall, P.S. Stevens \& T. Stüzel (eds.), The families and genera of plants, 4: 141-190. Springer Verlag, Berlin.

Govindarajalu, E. 1974. The systematic anatomy of south Indian Cyperaceae: Cyperus L. subgen. Juncellus, Cyperus subgen. Mariscus and Lipocarpha R. Br. Botanical Journal of the Linnean Society 68: 235-266.

Haines, R.W. \& K.A. Lye. 1983. The sedges and rushes of East Africa. East African Natural History Society, Nairobi. 404 pp.

Hauser, E.W. 1962. Development of purple nutsedge under field conditions. Weeds 10: 315-321.

Heinzen, F. 1993. Estudios morfológicos y ontogénicos de los sistemas de ramificación subterránea en Cyperus rotundus L. y C. corymbosus Rottb. var. subnodosus (Nees et Meyen) (Cyperaceae). Informe Final Beca de iniciación. Facultad de Ciencias Agrarias. Universidad Nacional del Litoral. 46 pp.

Heinzen, F.A. \& A.C. Vegetti. 1994. Typology of the Inflorescence in Cyperus corymbosus var. subnodosus and C. rotundus (Cyperaceae). Beiträge zur Biologie der Pflanzen 68: 263273.

Hilguert, N. 1993. Las comunidades vegetales de los departamentos Castellanos y Las Colonias (Santa Fe). Trabajo final de graduación. Fac. Cs. Exactas y Naturales (UNC). 45 p.

Holm, L.G., D.L. Plucknett, J.W. Pancho \& J.P. Herberger. 1977. The world's worst weeds. Distribution and Biology. Univ. Press Hawaii, Honolulu. 609 pp.

Hroudová, Z. \& P. ZÁKravsky. 1995. Bolboschoenus maritimus (L.) Palla - tuber production and dormancy in natural habitats. Abstracta Botanica 19: 89-94.

Justice, O.L. \& M.D. WhiteheAd. 1946. Seed production, viability, and dormancy in the nutgrasses Cyperus rotundus and $C$. esculentus. Journal of Agricultural Research 73: 303-318.

KRON, P. \& S.C. Stewart. 1994. Variability in the expression of a rhizome architecture model in a natural population of Iris versicolor (Iridaceae). American Journal of Botany 81: 1128-1138.

Kukkonen, I. 1967. Gedanken und Probleme zur Systematik der Familie Cyperaceae. Eine Zusammenfassung. Aquilo 6: $18-42$.

Li, M. \& M.B. Jones. 1995. $\mathrm{CO}_{2}$ and $\mathrm{O}_{2}$ transport in the aerenchyma of Cyperus papyrus L. Aquatic botany 52: 93-106.

Lorougnon, G. 1969. Etude morphologique et biologique du Cyperus rotundus L. Orstom Biology 10: 19-33.

Lorougnon, G. 1970. Morphogenèse et multiplication végétative de quelques Cypéracées. Annales des Sciences Naturelles; Botanique 12(12) : 179-232.

Loustalot, A.J., T.J. MuziK \& H.J. Cruzado. 1954. Studies on nutgrass (Cyperus rotundus L.) and its control. Mayaguez: Federal Experiment Station in Puerto Rico. Bulletin 52: $1-30$. 
Mani, A.P. 1963. Types of vascular bundles in Cyperus and their possible trend of specialization. Science and Culture 29:37-39.

Mehra, P.M. \& O.P. Sharma. 1965. Epidermical silica cells in the Cyperaceae. Botanical Gazette126: 53-58.

Mehra, P.M. \& O.P. Sharma. 1969. Systematic anatomy of Cyperus L. Research Bulletin Punjab University 20: 119-137.

Menezes, N.L., D.C. Silva, R.C.O. Arruda, G.F. Melo-de-Pinna, V.A. Cardoso, N.M. Castro, V.L. Scatena \& E. ScreminDiAs. 2005. Meristematic activity of the endodermis and the pericycle in the primary tickening in monocotyledons. Considerations on the "PTM". Anais da Academia Brasileira de Ciências 77: 259-274.

Metcalfe, C.R. 1971. Anatomy of the monocotiledons. V Cyperaceae. The Clarendon Press. Oxford. 597 pp.

Plowman, A.B. 1906. The comparative anatomy and Phylogeny of the Cyperaceae. Annals of Botany 20: 1-34.

Prata, A.P., N.L. Menezes, S.C. Mazzoni-Viveiros, M.G.L. WAnderley \& W.W. Thomas. 2007. Anatomia do escapo e rizoma de espécies brasileiras de Bulbostylis Kunth (Cyperaceae). Revista Brasileira de Botânica 30:245-256.

Rodrigues, A.C. \& M.E.M. EstelitA. 2002. Primary and secondary development of Cyperus giganteus Vahl rhizome (Cyperaceae). Revista Brasileira de Botânica 25: 251-258.

Rodrigues, A.C. \& M.E.M. Estelita. 2009. Morphoanatomy of the stem in Cyperaceae. Acta Botanica Brasilica 23(3) doi: 10.1590/S0102-33062009000300030.

Rudall, P. 1984. Taxonomic and evolutionary implications of rhizome structure and secondary thickening in Iridaceae. Botanical Gazette 145:524-534.

SCHMID, B. \& J.L. HARPER.1985. Clonal growth in grassland perennials. I. Density and pattern dependent competition between plants with different growth forms. Journal of Ecology 73: 793-808.

SCUlthorpe, C.D. 1967. The biology of aquatic vascular plants. Edward Arnold, London. 610 pp.
Shaн, C.K. 1967. Studies in the anatomy of the Cyperaceae. Vidya Journal Gujarat University 11: 226-239.

ShARMA, O.P.\& P.N. MEHRA. 1972. Systematic anatomy of Fimbristylis Vahl. (Cyperaceae). Botanical Gazette 133: 87-95.

Simpson, D., A. Muasya, M. Alves, J. Bruhl, S. Dhooge, M. Chase, C.A. Funes, K. Ghamkar, P. Goetghebeur, T.R. Hodkinson, A.D. Marchant, A. Reznicek, R. Nieuwborg, E.H. Roalson, E. Smets, J.R. Starr, W.W. Tomas, K.L. Wilson \& X. Zhang. 2007. Phylogeny of Cyperaceae based on DNA sequence data-a new $r b c L$ analysis. Aliso 23: $72-83$.

Stoller, E.W. \& D. Sweet. 1987. Biology and life cycle of purple and yellow nutsedges (Cyperus rotundus and C. esculentus) Weed Technology 1: 66-73.

Vegetti, A.C. 1993. Notas sobre Cyperaceae de la Provincia de Santa Fe: II. Los Géneros de Cyperaceae de la Provincia de Santa Fe. FAVE 7 (2): 31-37.

WiLle, F. 1926. Beiträge zur Anatomie des Cyperaceenrhizoms. Beihefte zum Botanischen Centralblatt: 43: 267-309.

WILls, G.D. 1975. Taxonomy, morphology, Anatomy, and composition of yellow nutsedge. Proceedings North Central Weed Control Conference. Milwaukee, Wisconsin. Vol 30: 121-124.

WILLS, G.D. 1987. Description of purple and yellow nutsedge (Cyperus rotundus and C. esculentus). Weed Technology 1: $2-9$.

Wills, G.D. \& G.A. Briscoe. 1970. Anatomy of purple nutsedge. Weed Science 18: 631-635.

Wills, G.D., R.E. Hoagland \& R.N. Paul. 1980. Anatomy of yellow nutsedge (Cyperus esculentus). Weed Science 28: 433-437.

Zoghbi, M., G.B. Das, E.H.A. Andrade, J. Oliveira, L.M.M. CArreira \& G.M.S.P. Guilhon. 2006. Yield and chemical composition of the essential oil of the stems and rhizomes of Cyperus articulatus L. cultivated in the state of Para, Brazil. Journal of Essential Oil Research 18(1): 10-12.

Recibido: 22.09.09

Aceptado: 13.05 .10 